Article

\title{
Action of Carvacrol on Parascaris sp. and Antagonistic Effect on Nicotinic Acetylcholine Receptors
}

\author{
Sasa M. Trailovic ${ }^{1}$, Milan Rajkovic ${ }^{1,2}{ }^{,}$Djordje S. Marjanovic ${ }^{1}$, Cédric Neveu ${ }^{3}$ and Claude L. Charvet ${ }^{3, *(1)}$ \\ 1 Department of Pharmacology and Toxicology, Faculty of Veterinary Medicine, University of Belgrade, \\ 11000 Belgrade, Serbia; sasa@vet.bg.ac.rs (S.M.T.); milan.rajkovic.vet@gmail.com (M.R.); \\ drdjolevet@yahoo.com (D.S.M.) \\ 2 Department of Biology, Faculty of Veterinary Medicine, University of Belgrade, 11000 Belgrade, Serbia \\ 3 INRAE, Université de Tours, ISP, 37380 Nouzilly, France; cedric.neveu@inrae.fr \\ * Correspondence: claude.charvet@inrae.fr
}

check for updates

Citation: Trailovic, S.M.; Rajkovic, M.; Marjanovic, D.S.; Neveu, C.; Charvet, C.L. Action of Carvacrol on Parascaris sp. and Antagonistic Effect on Nicotinic Acetylcholine Receptors. Pharmaceuticals 2021, 14, 505. https:// doi.org/10.3390/ph14060505

Academic Editor: Marcelo J. Nieto

Received: 24 April 2021

Accepted: 21 May 2021

Published: 26 May 2021

Publisher's Note: MDPI stays neutral with regard to jurisdictional claims in published maps and institutional affiliations.

Copyright: (c) 2021 by the authors. Licensee MDPI, Basel, Switzerland. This article is an open access article distributed under the terms and conditions of the Creative Commons Attribution (CC BY) license (https:// creativecommons.org/licenses/by/ $4.0 /)$.

\begin{abstract}
Parascaris sp. is the only ascarid parasitic nematode in equids and one of the most threatening infectious organisms in horses. Only a limited number of compounds are available for treatment of horse helminthiasis, and Parascaris sp. worms have developed resistance to the three major anthelmintic families. In order to overcome the appearance of resistance, there is an urgent need for new therapeutic strategies. The active ingredients of herbal essential oils are potentially effective antiparasitic drugs. Carvacrol is one of the principal chemicals of essential oil from Origanum, Thymus, Coridothymus, Thymbra, Satureja and Lippia herbs. However, the antiparasitic mode of action of carvacrol is poorly understood. Here, the objective of the work was to characterize the activity of carvacrol on Parascaris sp. nicotinic acetylcholine receptor (nAChR) function both in vivo with the use of worm neuromuscular flap preparations and in vitro with two-electrode voltage-clamp electrophysiology on nAChRs expressed in Xenopus oocytes. We developed a neuromuscular contraction assay for Parascaris body flaps and obtained acetylcholine concentration-dependent contraction responses. Strikingly, we observed that $300 \mu \mathrm{M}$ carvacrol fully and irreversibly abolished Parascaris sp. muscle contractions elicited by acetylcholine. Similarly, carvacrol antagonized acetylcholine-induced currents from both the nicotine-sensitive AChR and the morantel-sensitive AChR subtypes. Thus, we show for the first time that body muscle flap preparation is a tractable approach to investigating the pharmacology of Parascaris sp. neuromuscular system. Our results suggest an intriguing mode of action for carvacrol, being a potent antagonist of muscle nAChRs of Parascaris sp. worms, which may account for its antiparasitic potency.
\end{abstract}

Keywords: Parascaris; carvacrol; nicotinic acetylcholine receptors; muscle contraction; electrophysiology; Xenopus oocytes; mode of action

\section{Introduction}

Helminth infections of livestock are of considerable importance and cause major financial losses [1]. Parascaris sp. is the largest nematode parasite of equids, representing a major threat in equine medicine. Parascaris sp. worms have a very high prevalence especially in foals with important impact in terms of morbidity and mortality [2,3]. The worms remain in the intestine of the equids and are targets for anthelmintic drugs. Only a limited number of compounds are available for treatment of horse helminthiasis with the macrocyclic lactones being the most recently developed drug class of veterinary anthelmintics, marketed since the 1980s [1,4]. Anthelmintic resistance is a major problem in veterinary medicine, and Parascaris sp. worms have recently developed resistance to the three major anthelmintic families [5-9]. In order to overcome the appearance of resistance, there is an urgent need for new therapeutic strategies, especially new chemical entities [1,10]. Based on their pharmacological properties, the active ingredients of herbal essential oils are potentially 
effective antiparasitic drugs [11-13]. Carvacrol and thymol are monoterpenic phenol isomers and the principal chemicals of essential oil from Origanum, Thymus, Coridothymus, Thymbra, Satureja and Lippia herbs [14]. Carvacrol is known for its wide use in traditional pharmacopeia due to antimicrobial and disinfectant properties [15-17]. In addition, some studies previously indicated that carvacrol has antinematodal properties against pathogenic helminths such as the pig roundworm Ascaris suum [18], the sheep parasite Haemonchus contortus [19,20], the fish parasite Anisakis simplex [14,21] and plant parasitic nematodes [22], and it can also kill the free-living model nematode Caenorhabditis elegans [23-25]. However, the antiparasitic mode of action of monoterpenoid compounds is poorly understood, and their potential use against horse parasites has not yet been investigated. Previous studies evidenced that the anthelmintic effect of carvacrol might be mediated through different ligand-gated ion channel subtypes including tyramine, acetylcholine and GABA receptors of nematodes [18,25-28] as well as acetylcholinesterase [14].

Acetylcholine is a major excitatory neurotransmitter in both vertebrates and invertebrates. The nicotinic acetylcholine receptors (nAChRs) are major targets for antinematodal drugs such as pyrantel and levamisole [29,30]. They are members of the cys-loop ligandgated ion channel superfamily and consist of five subunits arranged around a central pore [31]. Despite the large diversity of $\mathrm{nAChR}$ subunit genes present in nematodes, few receptor subtypes have been characterized to date. Two nAChR subtypes have been described to mediate fast neurotransmission at the neuromuscular junction in the free-living model nematode Caenorhabditis elegans [32]: the levamisole-sensitive nAChR (L-AChR), which is a heteromeric ion channel made of five different subunits, and the prototypical nicotine-sensitive nAChR (N-AChR), which is composed of five identical subunits encoded by the Cel-acr-16 gene [33,34]. In parasites, the ACR-16 receptor subunit was recently isolated and characterized from Parascaris sp. as well as the pig parasite, Ascaris suum $[35,36]$. When expressed in Xenopus laevis oocytes, ACR-16 formed a functional homomeric N-AChR, which is activated by nicotine. Furthermore, a new subtype of nematode AChR preferentially activated by morantel was reported in Parascaris sp. (M-AChR) along with the small ruminant parasite Haemonchus contortus [29]. Interestingly, parasitic nematodes affecting humans or animals possess two closely related AChR subunit genes that are essentially absent in free-living or plant parasitic species: $a c r-26$ encodes an alpha subunit, and acr-27 encodes a non-alpha subunit. Hence, ACR-26 and ACR-27 subunits from Parascaris sp. were found to form a functional AChR when co-expressed in Xenopus oocytes, with higher affinities for pyrantel and morantel than for acetylcholine. Importantly, the heterologous expression of Parascaris-acr-26 and acr-27 as transgenes in the model nematode Caenorhabditis elegans also drastically increased morantel and pyrantel sensitivity in vivo [29].

Here, the objective of the work was to characterize and investigate the activity of carvacrol at different concentrations on Parascaris sp. nicotinic acetylcholine receptors both for $\mathrm{nAChR}$ function in vivo with the use of worm neuromuscular flap preparations and in vitro for nAChRs expressed in Xenopus oocytes. Strikingly, we observed that carvacrol abolished Parascaris sp. muscle contraction elicited by acetylcholine. Likewise, carvacrol inhibited acetylcholine-induced currents on both N-AChR and M-AChR subtypes. Thus, we show carvacrol is a potent antagonist of muscle AChRs, which may account for its antiparasitic potency against Parascaris sp. worms.

\section{Results}

\subsection{Acetylcholine-Induced Contraction of Parascaris sp. Body Muscle Flap Preparation}

Parascaris sp. and A. suum worms are closely related ascarid species with similar anatomy and morphology (Figure 1a). The presence of acetylcholine receptors on Parascaris sp. muscles is anticipated as every nematode is supposed to synthesize acetylcholine and receptors, although this has not yet been functionally evidenced. Therefore, as for A. suum, it is expected that the application of acetylcholine on Parascaris sp. muscle strips would produce muscle contractions. As a first step, we adapted the muscle isometric contraction 
approach, which previously was used in A. suum studies [26,37]. Due to worm size differences, we had to modify the method of dissection. The part of the Parascaris worm that we dissected for contractions was 4 to $5 \mathrm{~cm}$ behind the head instead of 2-3 cm for A. suum (Figure 1b). In addition, in order to cause contractions after acetylcholine application, we had to use a larger initial tension $(1.5 \mathrm{~g})$. On the other hand, the maximal contractions were no higher than the contractions previously obtained in A. suum experiments [26,37]. As a result, we were able to measure contractions of nerve-muscle strip preparations induced by ACh. Figure 1c shows a representative recording of the Parascaris sp. muscle flap contractions produced by increasing concentrations of acetylcholine, while in Figure 1d we present a concentration-response plot for ACh fitted with non-linear regression. Increasing concentrations of ACh caused dose-dependent contractions of Parascaris sp. The control median effective concentration $\left(\mathrm{EC}_{50}\right)$ of $\mathrm{ACh}$ was $6.08 \mu \mathrm{M}\left(\log \mathrm{EC}_{50}=0.78 \pm 0.079, n=5\right)$, while the maximal effect $\left(R_{\max }\right)$ was $1.19 \pm 0.051 \mathrm{~g}$ obtained with $100 \mu \mathrm{M}$ ACh. Overall, these results indicate that Parascaris sp. body muscle flap preparation is an amenable approach for investigating the pharmacology of its neuromuscular system.
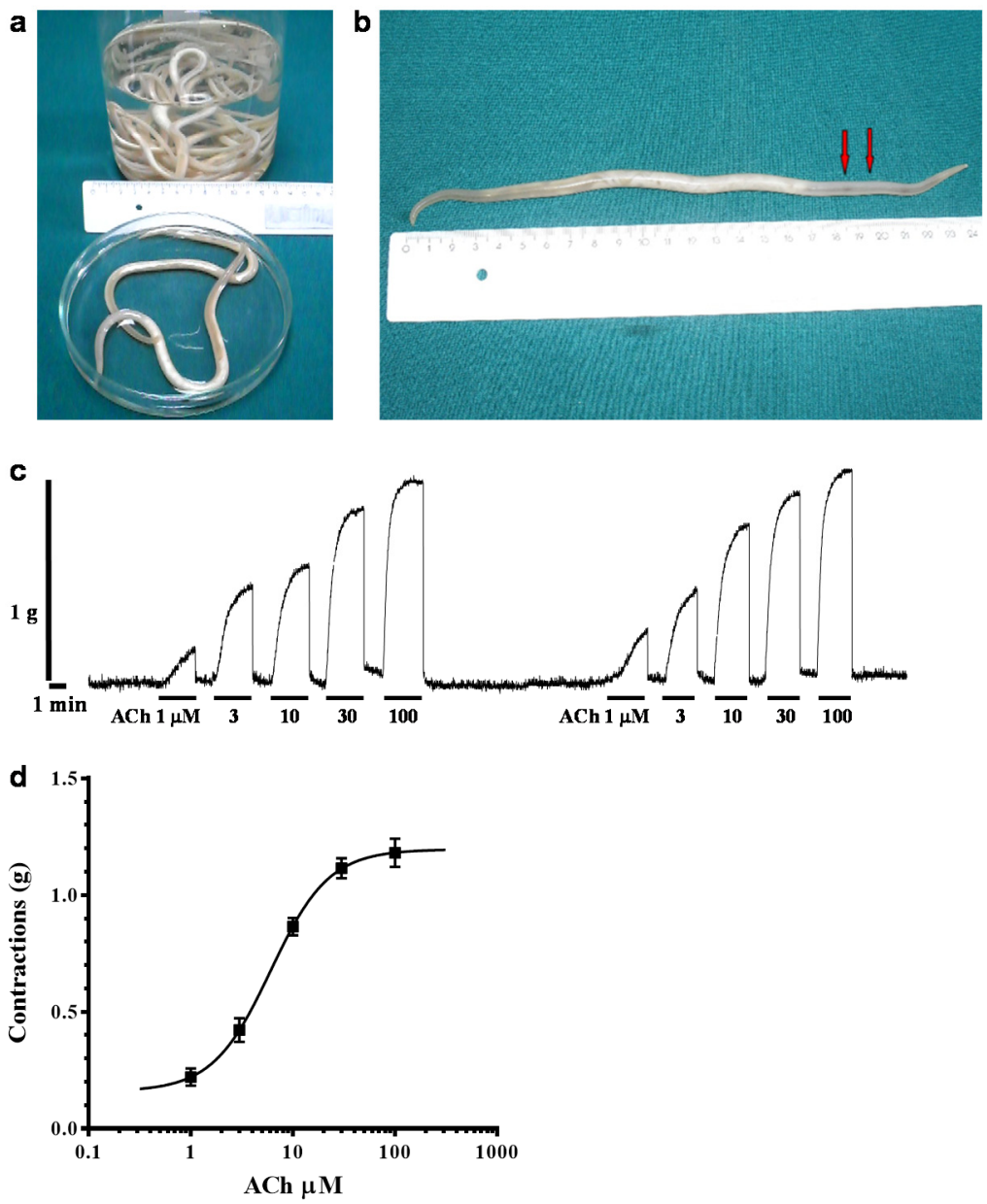

Figure 1. Contraction of Parascaris sp. muscle strips produced by acetylcholine. (a) Adult female Parascaris sp. collected from horses and used in this study; (b) photograph of a single worm indicating the location of the body muscle flap ( $1 \mathrm{~cm}$ length between the two red arrows), within the anterior part of the worm (3-4 cm caudal to the head), to be dissected for isometric contraction measurements; (c) isometric contractions of Parascaris sp. muscle flap produced by increasing concentrations of acetylcholine (ACh) from 1 to $100 \mu \mathrm{M}$ (short bars); (d) concentration-response plot for ACh fitted with non-linear regression, with mean contraction in $\mathrm{g} \pm \mathrm{SE}(n=5)$. 


\subsection{Carvacrol Abolishes Acetylcholine-Induced Contractions of Parascaris sp. Muscle Strips}

Previous studies highlighted the inhibitory effect of carvacrol on A. suum isolated muscle flap contractions caused by ACh $[26,28]$. In order to obtain first insights into the mode of action of carvacrol on Parascaris sp. worms, we determined the effect of carvacrol in isometric contractions of isolated segments of Parascaris sp. Figure 2 shows an inhibitory effect of carvacrol $(300 \mu \mathrm{M})$ on the contractions of nerve-muscle preparation of Parascaris sp. induced by ACh. Strikingly, carvacrol completely abolished the contraction induced by $\mathrm{ACh}$ even at $100 \mu \mathrm{M}$, which is the highest concentration assessed and was used to achieve the maximal contraction effect. Interestingly, the inhibitory effect of $300 \mu \mathrm{M}$ carvacrol remained even after removal of carvacrol from experimental baths. Altogether, our results show isometric contractions of Parascaris sp. muscle strips produced by increasing concentrations of $\mathrm{ACh}$ and full inhibition of contractions following application of carvacrol.

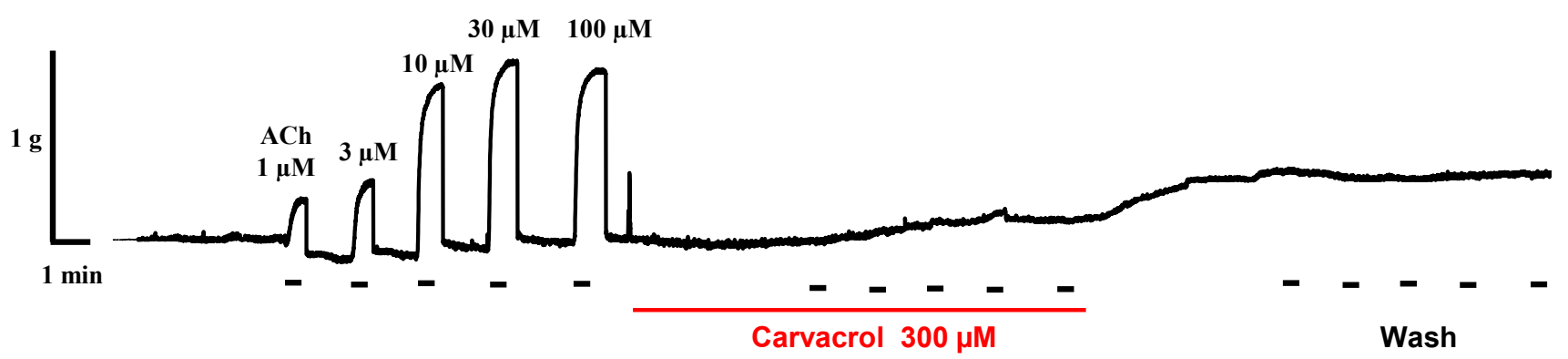

Figure 2. Effect of carvacrol on contractions of Parascaris sp. muscle strips produced by acetylcholine. Isometric contractions of Parascaris sp. muscle flap produced by increasing concentrations of acetylcholine (ACh) from 1 to $100 \mu \mathrm{M}$ (left panel, short bars) and inhibition of contractions mediated by $300 \mu \mathrm{M}$ carvacrol (middle panel, full line). Absence of ACh-induced response recovery after washing the preparation (right panel).

\subsection{Effect of Carvacrol on the Parascaris sp. Morantel-AChR Expressed in Xenopus oocytes}

It was recently described that the co-expression of the Parascaris sp. ACR-26 and ACR27 subunits in Xenopus laevis oocytes resulted in a functional morantel-sensitive AChR (MAChR) [29]. The expression of the Parascaris 26/27 M-AChR resulted in robust currents in the $\mu \mathrm{A}$ range when challenged with $100 \mu \mathrm{M}$ acetylcholine (Figure $3 \mathrm{a}$ ). The $\mathrm{ACh}^{\mathrm{E}} \mathrm{C}_{50}$ value of $25.0 \mu \mathrm{M}\left(\log \mathrm{EC}_{50}=1.398 \pm 0.022, n=6\right)$ was estimated from the concentration-response curve with current amplitudes normalized to the maximal response to $100 \mu \mathrm{M}$ (Figure 3c). When carvacrol was perfused in the recording chamber, we observed no agonist action on the M-AChR (Figure 3b). Strikingly, the continued perfusion of 100 and $300 \mu \mathrm{M}$ carvacrol during the $\mathrm{ACh}$ concentration-response relationships significantly decreased the $\mathrm{ACh}$ $\mathrm{EC}_{50}$ values to $12.2\left(\log \mathrm{EC}_{50}=1.085 \pm 0.064, n=5\right)$ and $6.6 \mu \mathrm{M}\left(\log \mathrm{EC}_{50}=0.817 \pm 0.060\right.$, $n=6)$, respectively $(p<0.0001)$. The Hill coefficients were determined and remained stable in the presence of either $100(1.7 \pm 0.4)$ or $300 \mu \mathrm{M}$ carvacrol $(1.5 \pm 0.3)$, compared to the absence of carvacrol (1.4 \pm 0.1$)$. In the same experiment, we observed that the perfusion of carvacrol significantly reduced the efficacy of ACh activation $\left(\mathrm{I}_{\max }\right)$ of this receptor $(p<0.0001)$ (Figure 3b). 
a

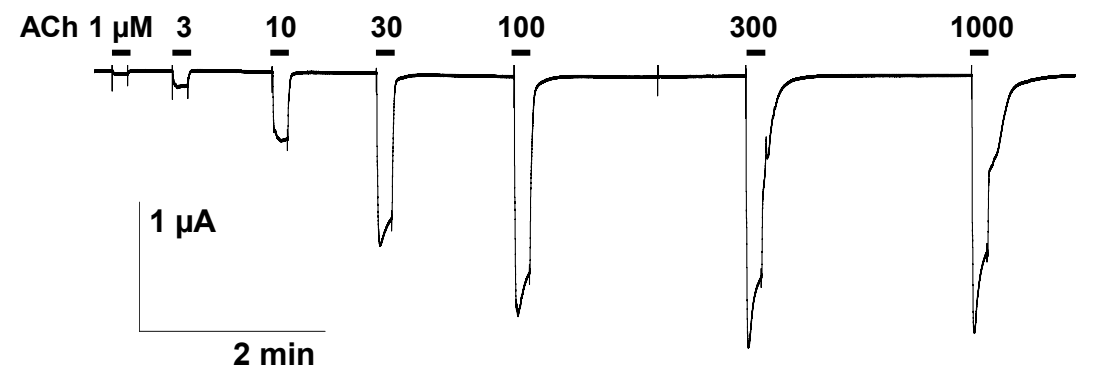

b

b Carvacrol $300 \mu \mathrm{M}$

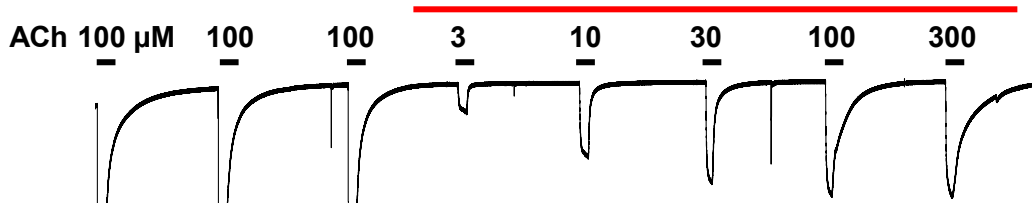

$1 \mu \mathrm{A}$

$2 \min$

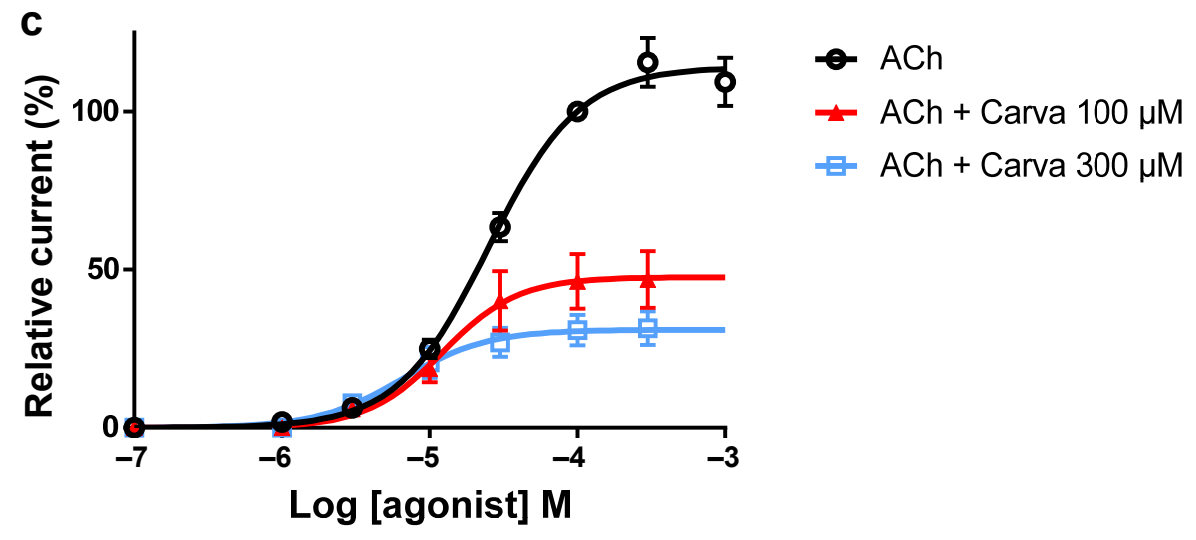

Figure 3. Concentration-response relationships of ACh on the Parascaris sp. ACR-26/27 M-AChR expressed in Xenopus laevis oocytes in absence of carvacrol (a) or in presence of carvacrol (b). Representative current traces for single oocytes. The concentrations of ACh and carvacrol $(\mu \mathrm{M})$ are indicated above each trace. Bars indicate drug applications: ACh was applied for $10 \mathrm{~s}$. (c) Concentrationresponse curves. All responses are normalized to $100 \mu \mathrm{M}$ ACh. Results are shown as the mean $\pm \mathrm{SE}$ $(n=5-6)$.

To characterize this effect, the carvacrol antagonist concentration-response relationship was obtained by perfusing oocytes with increasing concentrations of carvacrol for $10 \mathrm{~s}$ prior to the co-application with $100 \mu \mathrm{M}$ ACh (Figure 4a,b). Hence, increasing concentrations of carvacrol $(10 \mu \mathrm{M}$ to $1 \mathrm{mM})$ resulted in a dose-dependent reduction of the maximal ACh-elicited current amplitude. The $\mathrm{IC}_{50}$ value of carvacrol for the Parascaris M-AChR was $169.3 \pm 1.0 \mu \mathrm{M}(n=7)$ (Figure 4c). Thus, carvacrol slightly increased the ACh affinity for the Parascaris M-AChR while acting as a non-competitive antagonist. 

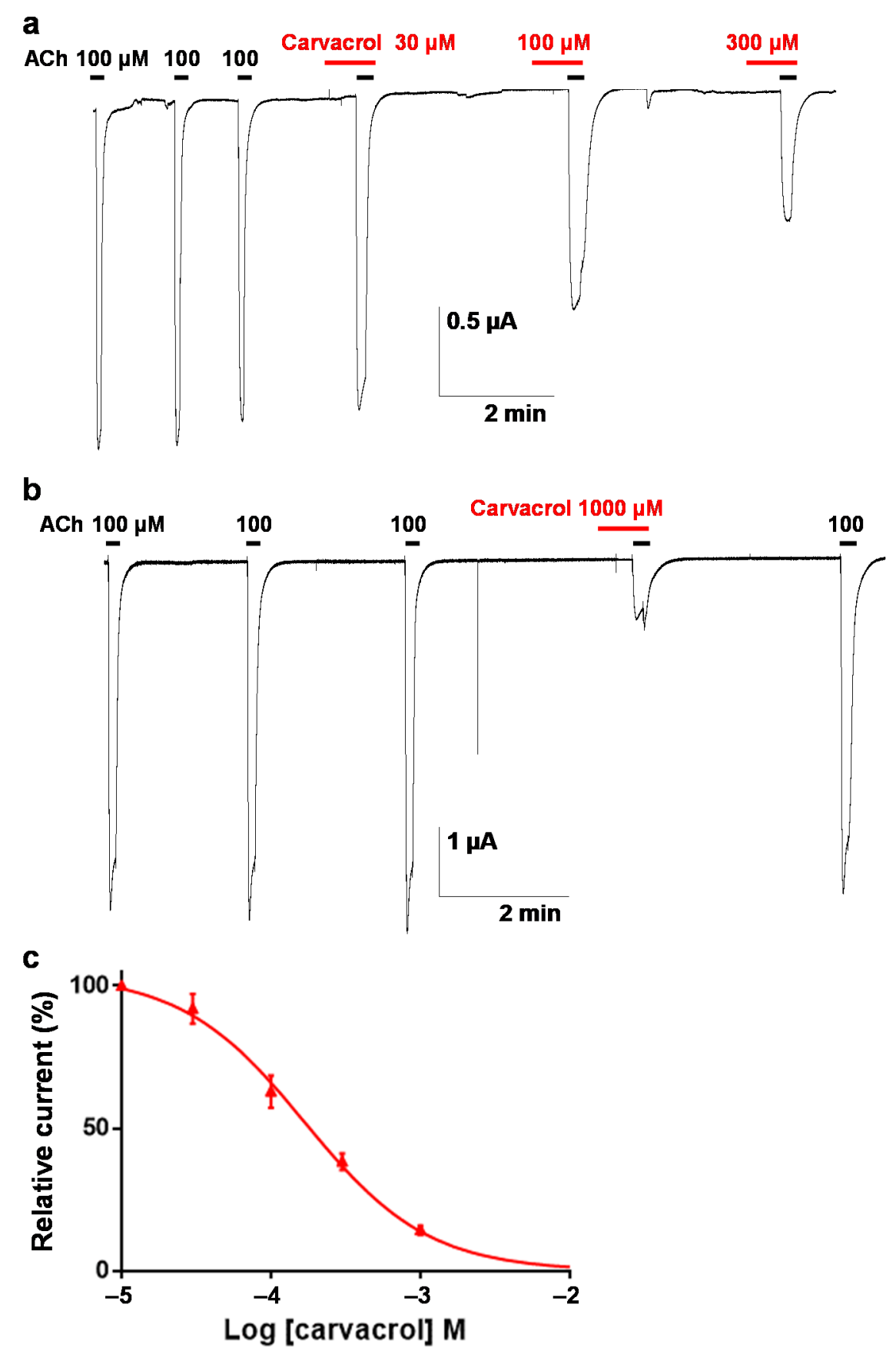

Figure 4. Concentration-inhibition relationship of carvacrol on the Parascaris sp. ACR-26/27 MAChR expressed in Xenopus oocytes. Representative current traces for single oocytes challenged with acetylcholine (ACh) in the presence of increasing concentration of carvacrol from 30 to 300 (a) and $1000 \mu \mathrm{M}(\mathbf{b})$. The concentrations of ACh and carvacrol $(\mu \mathrm{M})$ are indicated above each trace. ACh was applied for $10 \mathrm{~s}$ (black bars), and carvacrol was applied for $20 \mathrm{~s}$ (red bars). (c) Concentrationinhibition response curve of carvacrol. All responses are normalized to $100 \mu \mathrm{M}$ ACh. Results are shown as the mean $\pm \operatorname{SE}(n=7)$.

2.4. Effect of Carvacrol on Parascaris sp. and Ascaris suum Nicotine-Sensitive AChRs Expressed in Xenopus oocytes

It was previously reported that the ACR-16 AChR subunit from Parascaris sp. and from the closely related species $A$. suum were able to form homomeric functional N-AChRs when expressed in Xenopus oocytes [35,36]. Recently, carvacrol proved to be a non-competitive inhibitor of the A. suum N-AChR [27]. In order to investigate the mode of action of carvacrol 
in Parascaris sp., we applied carvacrol on oocytes expressing the Parascaris sp. N-AChR (Figure $5 \mathrm{~b}$ ). Perfusion of $100 \mu \mathrm{M}$ acetylcholine elicited large currents with maximum amplitude in the $\mu \mathrm{A}$ range (Figure $5 \mathrm{a}$ ), and the $\mathrm{ACh}$ concentration-response curve was characterized by an $\mathrm{EC}_{50}$ of $6.5 \mu \mathrm{M}\left(\log \mathrm{EC}_{50}=0.811 \pm 0.028, n=6\right)$ (Figure $\left.5 \mathrm{c}\right)$. As expected, a high concentration of carvacrol $(300 \mu \mathrm{M})$ had no agonist effect (Figure $5 \mathrm{~b})$. In the presence of 100 and $300 \mu \mathrm{M}$ of carvacrol, the $\mathrm{EC}_{50}$ values of $\mathrm{ACh}$ were $5.9\left(\log \mathrm{EC}_{50}=0.772 \pm 0.052\right.$, $n=6)$ and $8.2 \mu \mathrm{M}\left(\log \mathrm{EC}_{50}=0.913 \pm 0.038, n=10\right)$, respectively, and not significantly different from the $\mathrm{ACh} \mathrm{EC}_{50}$ obtained without carvacrol (Figure $5 \mathrm{c}$ ). As for the $\mathrm{M}-\mathrm{AChR}$, the Hill coefficients were similar with values of $2.0 \pm 0.3,2.1 \pm 0.4$ and $2.0 \pm 0.2$ for 100, $300 \mu \mathrm{M}$ carvacrol and without carvacrol, respectively. However, the ACh maximal response amplitude was significantly reduced by 2- and 3-fold in the presence of 100 and $300 \mu \mathrm{M}$ of carvacrol $(p<0.05)$, respectively. Thus, ACh had a lower efficacy as an agonist of the Parascaris N-AChR in the presence of carvacrol.

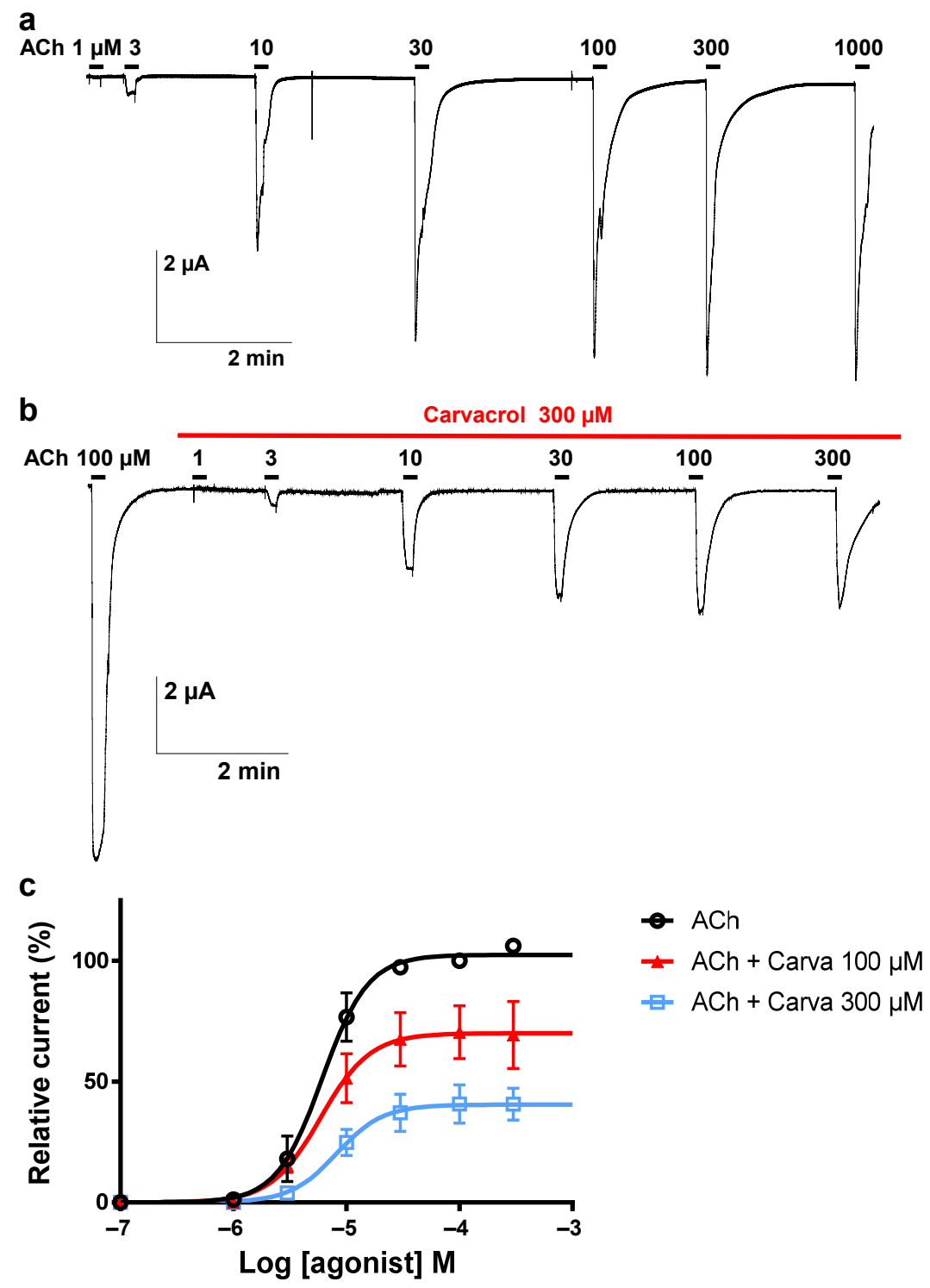

Figure 5. Carvacrol effect on the ACh concentration-response relationships for the Parascaris sp. ACR-16 N-AChR expressed in Xenopus oocytes in absence of carvacrol (a) or in presence of carvacrol (b). Representative current traces for single oocytes. The concentrations of ACh and carvacrol $(\mu \mathrm{M})$ are indicated above each trace. Bars indicate drug applications: ACh was applied for $10 \mathrm{~s}$, and carvacrol was applied for $11 \mathrm{~min}$ (red bar). (c) Concentration-response curves. All responses are normalized to $100 \mu \mathrm{M}$ ACh. Results are shown as the mean \pm SE $(n=6-10)$. 
To characterize this inhibition, carvacrol was perfused during the application of ACh as described elsewhere for different synthetic compounds (Figure 6a) [38]. The carvacrol antagonist concentration-response relationship (10 $\mu \mathrm{M}$ to $1 \mathrm{mM})$ resulted in a dose-dependent inhibition of the currents with an $\mathrm{IC}_{50}$ value of $177.8 \pm 1.1 \mu \mathrm{M}(n=6)$ (Figure 6b). Similarly, we confirmed that $100 \mu \mathrm{M}$ carvacrol had no impact on the $\mathrm{ACh}^{\mathrm{EC}} \mathrm{C}_{50}$ value for the $\mathrm{A}$. suum $\mathrm{N}-\mathrm{AChR}(6.0 \pm 1.0(n=6)$ versus $4.9 \pm 1.1 \mu \mathrm{M}(n=11)$ without carvacrol, $p>0.05)$. In addition, we extended this observation to $300 \mu \mathrm{M}$ carvacrol $(8.9 \pm 1.1 \mu \mathrm{M}(n=5))$ (Figure S1). As previously described [27], $100 \mu \mathrm{M}$ carvacrol led to a significant decrease in the ACh maximum response $(73.6 \pm 1.7 \%, p<0.05, n=6)$. Increasing the carvacrol concentration to $300 \mu \mathrm{M}$ drastically reduced the effect of $\mathrm{ACh}(19.6 \pm 1.5 \%, p<0.05, n=5)$. In addition, we determined a carvacrol antagonist dose-response relationship for the $A$. suum $\mathrm{N}-\mathrm{AChR}$ and obtained an $\mathrm{IC}_{50}$ value of $36.4 \pm 1.3 \mu \mathrm{M}(n=6)$ (Figure S2). Altogether, these results indicate that carvacrol acted as a non-competitive antagonist on Parascaris sp. and A. suum N-AChRs.

a
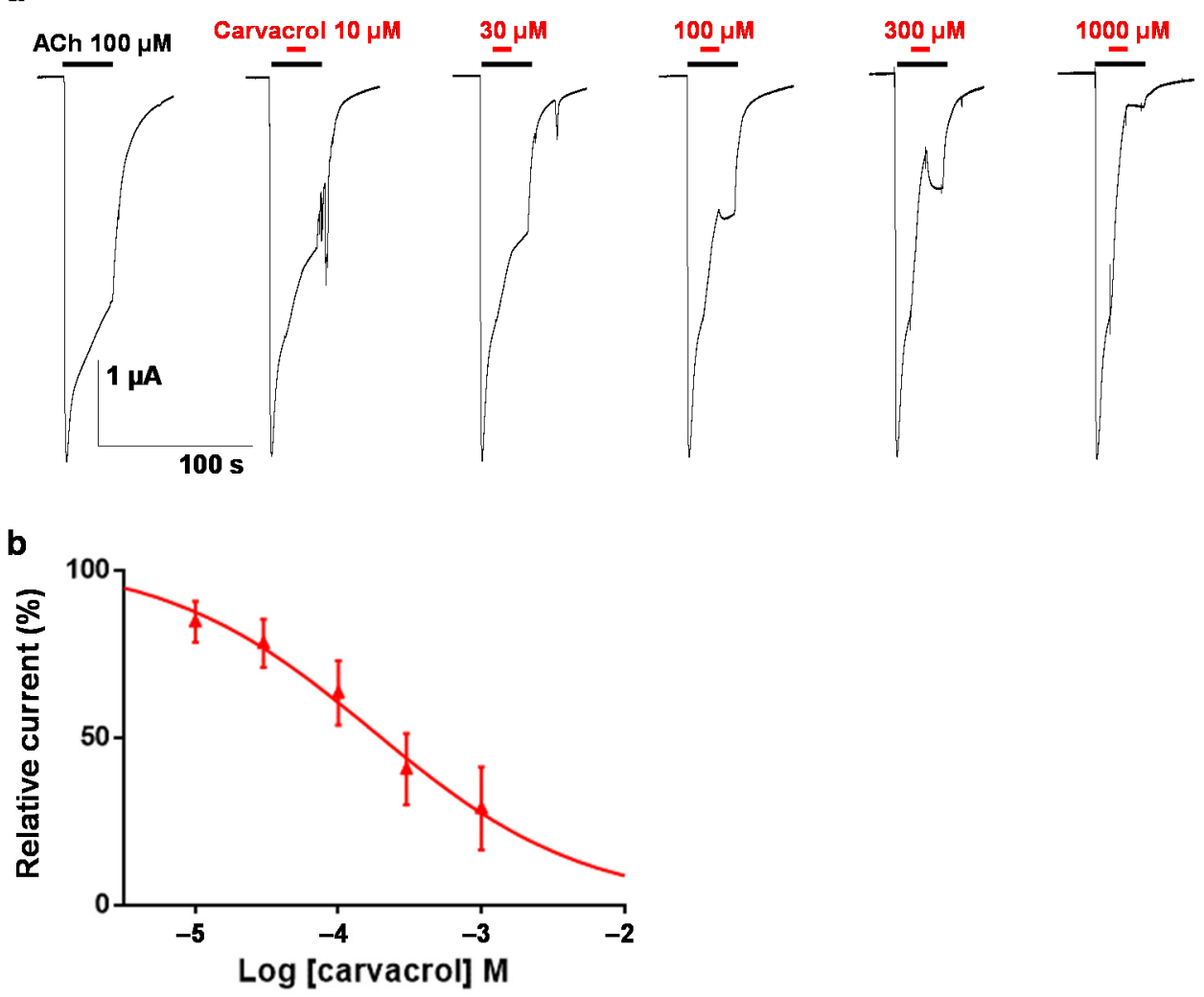

Figure 6. Concentration-inhibition relationship of carvacrol on the Parascaris sp. ACR-16 N-AChR expressed in Xenopus oocytes. (a) Representative current traces for single oocytes challenged with acetylcholine (ACh) in the presence of increasing concentration of carvacrol from 10 to $1000 \mu \mathrm{M}$. The concentrations of ACh and carvacrol $(\mu \mathrm{M})$ are indicated above each trace. ACh was applied for $30 \mathrm{~s}$ intervals (black bars), and carvacrol was applied for $10 \mathrm{~s}$ (red bars). (b) Concentration-inhibition response curve of carvacrol. All responses are normalized to $100 \mu \mathrm{M}$ ACh. Results are shown as the mean \pm SE $(n=6)$.

\section{Discussion}

There has been limited published data reporting the contraction force transduction in adult parasite worms. In the present study, we carried out for the first time an investigation of Parascaris sp. worm pharmacology using contraction assays performed on nerve-muscle preparations. The contractions are not different from the contractions that were obtained in nerve-muscle preparation prepared from $A$. suum, except that the maximal effect is 
somewhat lower. Indeed, the $\mathrm{EC}_{50}$ of $\mathrm{ACh}$ from $6.08 \mu \mathrm{M}$ is similar to the values ranging from 8.87 to $10.88 \mu \mathrm{M}$ observed in A. suum innervated muscle strips [26,37]. These first results indicate that the body muscle flap preparation is a tractable approach to study the pharmacology of the Parascaris sp. neuromuscular system. In addition to A. suum [39], the measurements of force transduction were described for the sheep barber pole worm Haemonchus contortus [40] and the canine hookworm Ancylostoma caninum, [41]. Interestingly, these studies provided a better understanding of the diversity of body wall muscle $\mathrm{nAChR}$ subtypes that are preferentially activated or antagonized by different cholinergic anthelmintics [42]. In this context, it would be reasonable to expect that the muscle isometric contraction approach could be further adapted for pharmacological investigations in other nematode parasite species of interest such as the ascarids Taxocara canis, Ascaridia galli and Anisakis simplex. Furthermore, when anthelmintic-resistant parasites were available, the comparison of muscle contraction assays with drug-susceptible nematode parasites revealed new insights into the mechanisms underpinning resistance to anthelmintics [40,41]. As little is known on the effect of cholinergic anthelmintics on Parascaris sp. Muscles, the muscle contraction approach will be useful for to assess the nAChRs present in Parascaris sp. and the changes that could be associated with resistance. In C. elegans, A. suum and the pig nodule worm Oesophagostomum dentatum, single channel recordings revealed at least three main $n A C h R$ subtypes characterized by their conductance [43-45]. Likewise, single channel experiments in somatic muscle cells of Parascaris sp. could be helpful to investigate the muscle $\mathrm{nAChR}$ subtypes targeted by anthelmintics and carvacrol in vivo.

Given the limited number of anthelmintic drugs available for the control of Parascaris sp. infestations (benzimidazole, pyrantel, ivermectin and moxidectin) and the growing issue of anthelmintic resistance worldwide, there is an urgent need to develop new alternative control strategies $[7,10]$. Hence, increasing attention is given to the nematocidal potential of plant-based natural products [46], including essential oils, which could replace or potentiate the effects of classical anthelmintic drugs [12]. The advantage of this approach is the possibility of continuous application of functional feeds, thus preventing reinfection after deworming, which does not provide long-term protection against infection. Among the active ingredients from essential oils, carvacrol was shown to be active against animal parasitic nematodes, plant parasitic nematodes and the free-living nematode $C$. elegans $[18,22,46]$. Here, we took advantage of the adapted neuromuscular contraction approach to assess the effect of carvacrol in Parascaris sp. We found that carvacrol completely abolished the contractions induced by $\mathrm{ACh}$, and this effect remained even after removal of carvacrol from the experimental bath. Based on this result, we hypothesized that carvacrol may interact directly with nAChRs. We would like to comment on the fact that after incubation of the neuromuscular flaps with $300 \mu \mathrm{M}$ of carvacrol, it was not possible to obtain contractions again. In our previous studies on $A$. suum, the effect was reversible, and contractions almost reached the control value after washing. Given the results obtained after receptor expression on oocytes, we hypothesize that the reason for this nature of carvacrol action is the anatomical and morphological specificity of Parascaris sp. that we observed. Namely, we assume there may be a kind of cumulative effect of carvacrol and the impossibility of its removal by washing. The body wall of Parascaris sp. is $2-3 \mathrm{~mm}$ thicker than in A. suum, due to the three-layer collagen sheath that holds the carvacrol and makes it impossible to wash. This assumption should certainly be examined in future research.

Our electrophysiological investigations demonstrated the non-competitive inhibition of carvacrol on both the nicotine-sensitive ACR-16 and the morantel-sensitive ACR-26/27 AChRs from Parascaris sp. expressed in Xenopus oocytes. In addition, this effect was further confirmed for the ACR-16 N-AChR from A. suum, which is closely phylogenetically related to Parascaris sp. This not the first time that carvacrol has been assayed on A. suum $\mathrm{nAChRs}$. It was previously observed that carvacrol produced significant inhibition of A. suum muscle contractions induced by $\mathrm{ACh}$, inhibited depolarizations caused by acetylcholine and reduced membrane conduction of muscle cells [26]. Unlike menthol, carvacrol has 
further been reported to produce non-competitive inhibition on the A. suum ACR-16 N$\mathrm{AChR}$ [27]. More recent contraction experiments revealed the antagonistic interaction of carvacrol with anthelmintic drugs at different muscle nicotinic receptors in vivo [28]. Interestingly, the full inhibition of the ACh contractile effect with $300 \mu \mathrm{M}$ of carvacrol was markedly different from the effect in A. suum, which did not exceed 49\% [26,28]. This result suggests that Parascaris worms may be more sensitive to carvacrol than Ascaris worms. On the other hand, our data are consistent with the results for A. suum ACR-16 N-AChRs, in which carvacrol acted as a non-competitive antagonist [27]. In addition, we further confirmed this effect on Parascaris sp. ACR-16 N-AChRs and extended to the ACR-26/27 M-AChRs. However, according to our concentration-inhibition data, carvacrol showed approximately 5-fold higher affinity for the A. suum N-AChR over the Parascaris sp. N -AChR. Therefore, it is not possible to rule out that additional mechanisms may be involved in the activity of carvacrol in Parascaris sp.

Noticeably, carvacrol and cinnamaldehyde showed a better potency in multi-drug resistant $H$. contortus egg hatch assay when combined together, and this result highlights the anthelmintic value of bioactive compounds from plant sources [20]. However, the literature is scarce on the clinical efficacy of herbal essential oils either alone or in combination with synthetic drugs in vivo, whereas numerous studies have shown interesting effects in vitro. Some recent investigations on plant product combination with anthelmintic drugs have reported potentially interesting synergistic effects against gastrointestinal parasites [47-49]. The potential of carvacrol and essential oils either alone or in association with anthelmintic drugs in treating Parascaris sp. infections in equids remains to be evaluated.

\section{Materials and Methods}

\subsection{Parascaris sp. Muscle Flap Contraction}

For the contraction assay, adult female Parascaris sp. worms were collected weekly from the slaughterhouse at Vrčin, Belgrade, Serbia. Worms were maintained in Locke's solution, composition (mM): $\mathrm{NaCl} 155, \mathrm{KCl} 5, \mathrm{CaCl}_{2} 2, \mathrm{NaHCO}_{3} 1.5$ and glucose 5, at a temperature of $32{ }^{\circ} \mathrm{C}$. The Locke's solution was changed twice daily, and each batch of worms was used within 2 days of collection. Parascaris muscle flaps for the contractions were prepared by dissecting the anterior part of the worm, 3-4 cm caudal to the head (Figure 1b). Each flap (always the same length of $1 \mathrm{~cm}$ ) was monitored isometrically by attaching a force transducer in an experimental bath maintained at $37^{\circ} \mathrm{C}$, containing $20 \mathrm{~mL}$ Ascaris Perienteric Fluid Ringer/APF Ringer (mM: NaCl, 23; Na-acetate, 110; KCl, 24; $\mathrm{CaCl}_{2}, 6 ; \mathrm{MgCl}_{2}$, 5; glucose, 11; HEPES, 5; pH 7.6) and bubbled with room air. After dissection, the preparations were allowed to equilibrate for $15 \mathrm{~min}$ under an initial tension of $1.5 \mathrm{~g}$. Different concentrations of ACh were then added to the preparation $(1,3,10,30$ and $100 \mu \mathrm{M}$ ), and the maximum contraction was observed before washing and subsequent application of the next concentration of acetylcholine. Responses for each concentration were expressed in grams of tension $(\mathrm{g})$, produced by each individual flap preparation. The effect of carvacrol $(300 \mu \mathrm{M})$ on the acetylcholine dose-response plots was determined. Contractions were monitored on a PC using a BioSmart interface and eLAB software (ElUnit, Belgrade, Serbia). The system allows real-time recording, display and analysis of experimental data. Sigmoid dose-response curves for each individual flap preparation at each concentration of the antagonist were described by the Hill equation.

\subsection{Two-Electrode Voltage-Clamp Electrophysiology in Xenopus laevis oocytes}

Parascaris sp. ACR-26/27 M-AChR as well as Parascaris sp. and A. suum ACR-16 NAChRs were expressed in Xenopus laevis oocytes as previously described [29,35,36]. Briefly, Xenopus laevis defolliculated oocytes were obtained from Ecocyte Bioscience (Germany). Oocytes were micro-injected with $36 \mathrm{~nL}$ of cRNA mixes containing $50 \mathrm{ng} / \mu \mathrm{L}$ of each cRNA encoding subunits of interest and three $H$. contortus ancillary factors (Hco-RIC-3.1, Hco-UNC-50 and Hco-UNC-74). After 3-4 days of incubation, the oocytes were assayed under voltage clamp at $-60 \mathrm{mV}$, and electrophysiological recordings were performed as 
described previously. The carvacrol concentration-dependent inhibition of acetylcholine current response was assessed for Parascaris- and Asu-ACR-16 channels with the protocol described by Zheng et al. [38].

\subsection{Drugs}

Acetylcholine chloride (ACh) and carvacrol were purchased from Sigma-Aldrich.

\subsection{Statistical Analyses}

The results of the contraction assay are expressed as means \pm S.E. in grams $(\mathrm{g})$ of tension. Sigmoid concentration dose-response is described by the equation as follows: $\%$ response $=1 / 1+[\mathrm{EC} 50 / \mathrm{Xa}] \mathrm{nH}$, where the median effective concentration $\left(\mathrm{EC}_{50}\right)$ is the concentration of the agonist (Xa) producing $50 \%$ of the maximum response, and $\mathrm{nH}$ is the Hill coefficient (slope). GraphPad Prism ${ }^{\circledR}$ Software (San Diego, CA, USA) was used to estimate the constants $\mathrm{EC}_{50}$ and $\mathrm{nH}$ by non-linear regression for each preparation. We determined the mean contraction responses to each concentration of acetylcholine. Whole cell current electrophysiology responses were analyzed using the pCLAMP 10.4 package (Molecular Devices). $\mathrm{EC}_{50}$ and $\mathrm{IC}_{50}$ values were determined using non-linear regression on normalized data (100 $\mu \mathrm{M}$ ACh as maximal response) using GraphPad Prism ${ }^{\circledR}$ software. One-way analysis of variance (ANOVA) was applied for the comparison of the differences between the $\mathrm{EC}_{50}$ value and the maximal effect $\left(\mathrm{R}_{\max }\right)$. Differences were considered significant when the $p$ value was $<0.05$. The statistical analysis was conducted using GraphPad Prism ${ }^{\circledR}$ software (San Diego, CA, USA), while all values are expressed as mean \pm standard error (S.E.).

\section{Conclusions}

In summary, we report for the first time in vivo contraction assays from Parascaris sp. neuromuscular preparation. Our findings indicate that the antimicrobial agent carvacrol inhibited nAChR function in vivo on Parascaris sp. muscle contractions and in vitro on both morantel- and nicotine-sensitive nAChRs. The present study improves the understanding of the anthelmintic mode of action of plant essential oil ingredients and opens the way for new therapeutic prospects in equine medicine.

Supplementary Materials: The following are available online at https:/ /www.mdpi.com/article/10 .3390/ph14060505/s1, Figure S1: Carvacrol effect on the acetylcholine concentration-response relationships for the Ascaris suum ACR-16 N-AChR expressed in Xenopus oocytes, Figure S2: Concentrationinhibition relationship of carvacrol on the A. suum ACR-16 N-AChR expressed in Xenopus oocytes.

Author Contributions: Conceptualization, S.M.T. and C.L.C.; methodology, S.M.T., M.R., D.S.M. and C.L.C.; investigation, S.M.T., M.R., D.S.M. and C.L.C.; formal analysis, S.M.T. and C.L.C.; data curation and visualization, S.M.T., M.R., D.S.M. and C.L.C.; writing-original draft preparation, C.L.C.; writing — review and editing, S.M.T., C.N. and C.L.C.; supervision, S.M.T. and C.L.C.; funding acquisition, S.M.T., M.R. and C.L.C. All authors have read and agreed to the published version of the manuscript.

Funding: This research program was supported by INRAE (http:/ /www.inrae.fr/), and the Ministry of Education, Science and Technological Development of the Republic of Serbia (Contract number 451-03-9/2021-14). This work was also supported by the France-Serbia Hubert Curien Partnerships program Pavle Savic 2016-2017 (project number 36256QA). M.R. was the grateful recipient of a travel grant from the RTR "Fédération de Recherche en Infectiologie (FéRI) de la Région Centre-Val de Loire" no. 201400094437 (https:/ /www.infectiologie-regioncentre.fr/) and a 2017-18 Burroughs Wellcome Fund Collaborative Research Travel Award.

Institutional Review Board Statement: Not applicable.

Informed Consent Statement: Not applicable.

Data Availability Statement: Data sharing not applicable. 
Conflicts of Interest: The authors declare no conflict of interest. The funders had no role in the design of the study; in the collection, analyses or interpretation of data; in the writing of the manuscript or in the decision to publish the results.

\section{References}

1. Nielsen, M.K. Universal challenges for parasite control: A perspective from equine parasitology. Trends Parasitol. 2015, 31, 282-284. [CrossRef]

2. Reinemeyer, C.R.; Nielsen, M.K. Parasitism and colic. Vet. Clin. N. Am. Equine Pract. 2009, 25, 233-245. [CrossRef]

3. Salle, G.; Guillot, J.; Tapprest, J.; Foucher, N.; Sevin, C.; Laugier, C. Compilation of 29 years of postmortem examinations identifies major shifts in equine parasite prevalence from 2000 onwards. Int. J. Parasitol. 2020, 50, 125-132. [CrossRef]

4. Gokbulut, C.; McKellar, Q.A. Anthelmintic drugs used in equine species. Vet. Parasitol. 2018, 261, 27-52. [CrossRef]

5. von Samson-Himmelstjerna, G. Anthelmintic resistance in equine parasites-detection, potential clinical relevance and implications for control. Vet. Parasitol. 2012, 185, 2-8. [CrossRef]

6. Matthews, J.B. Anthelmintic resistance in equine nematodes. Int. J. Parasitol. Drugs Drug Resist. 2014, 4, 310-315. [CrossRef]

7. Nielsen, M.K.; Reinemeyer, C.R.; Donecker, J.M.; Leathwick, D.M.; Marchiondo, A.A.; Kaplan, R.M. Anthelmintic resistance in equine parasites-current evidence and knowledge gaps. Vet. Parasitol. 2014, 204, 55-63. [CrossRef]

8. Peregrine, A.S.; Molento, M.B.; Kaplan, R.M.; Nielsen, M.K. Anthelmintic resistance in important parasites of horses: Does it really matter? Vet. Parasitol. 2014, 201, 1-8. [CrossRef]

9. Martin, F.; Hoglund, J.; Bergstrom, T.F.; Karlsson Lindsjo, O.; Tyden, E. Resistance to pyrantel embonate and efficacy of fenbendazole in Parascaris univalens on Swedish stud farms. Vet. Parasitol. 2018, 264, 69-73. [CrossRef]

10. Raza, A.; Qamar, A.G.; Hayat, K.; Ashraf, S.; Williams, A.R. Anthelmintic resistance and novel control options in equine gastrointestinal nematodes. Parasitology 2019, 146, 425-437. [CrossRef]

11. Anthony, J.P.; Fyfe, L.; Smith, H. Plant active components-a resource for antiparasitic agents? Trends Parasitol. 2005, 21, 462-468. [CrossRef]

12. Kaplan, R.M.; Storey, B.E.; Vidyashankar, A.N.; Bissinger, B.W.; Mitchell, S.M.; Howell, S.B.; Mason, M.E.; Lee, M.D.; Pedroso, A.A.; Akashe, A.; et al. Antiparasitic efficacy of a novel plant-based functional food using an Ascaris suum model in pigs. Acta Trop. 2014, 139, 15-22. [CrossRef]

13. Saha, S.; Lachance, S. Effect of essential oils on cattle gastrointestinal nematodes assessed by egg hatch, larval migration and mortality testing. J. Helminthol. 2019, 94, e111. [CrossRef]

14. Lopez, V.; Cascella, M.; Benelli, G.; Maggi, F.; Gomez-Rincon, C. Green drugs in the fight against Anisakis simplex-larvicidal activity and acetylcholinesterase inhibition of Origanum compactum essential oil. Parasitl. Res. 2018, 117, 861-867. [CrossRef]

15. Baser, K.H. Biological and pharmacological activities of carvacrol and carvacrol bearing essential oils. Curr. Pharm. Des. 2008, 14, 3106-3119. [CrossRef]

16. Friedman, M. Chemistry and multibeneficial bioactivities of carvacrol (4-isopropyl-2-methylphenol), a component of essential oils produced by aromatic plants and spices. J. Agric. Food Chem. 2014, 62, 7652-7670. [CrossRef]

17. Sakkas, H.; Papadopoulou, C. Antimicrobial Activity of Basil, Oregano, and Thyme Essential Oils. J. Microbiol. Biotechnol. 2017, 27, 429-438. [CrossRef]

18. Lei, J.; Leser, M.; Enan, E. Nematicidal activity of two monoterpenoids and SER-2 tyramine receptor of Caenorhabditis elegans. Biochem. Pharmacol. 2010, 79, 1062-1071. [CrossRef]

19. Andre, W.P.; Ribeiro, W.L.; Cavalcante, G.S.; dos Santos, J.M.; Macedo, I.T.; de Paula, H.C.; de Freitas, R.M.; de Morais, S.M.; de Melo, J.V.; Bevilaqua, C.M. Comparative efficacy and toxic effects of carvacryl acetate and carvacrol on sheep gastrointestinal nematodes and mice. Vet. Parasitol. 2016, 218, 52-58. [CrossRef]

20. Katiki, L.M.; Barbieri, A.M.E.; Araujo, R.C.; Verissimo, C.J.; Louvandini, H.; Ferreira, J.F.S. Synergistic interaction of ten essential oils against Haemonchus contortus in vitro. Vet. Parasitol. 2017, 243, 47-51. [CrossRef]

21. Hierro, I.; Valero, A.; Perez, P.; Gonzalez, P.; Cabo, M.M.; Montilla, M.P.; Navarro, M.C. Action of different monoterpenic compounds against Anisakis simplex s.1. L3 larvae. Phytomedicine 2004, 11, 77-82. [CrossRef]

22. Andres, M.F.; Gonzalez-Coloma, A.; Sanz, J.; Burillo, J.; Sainz, P. Nematicidal activity of essential oils: A review. Phytochem. Rev. 2012, 11, 371-390. [CrossRef]

23. Abdel-Rahman, F.H.; Alaniz, N.M.; Saleh, M.A. Nematicidal activity of terpenoids. J. Environ. Sci. Health B 2013, 48, 16-22. [CrossRef]

24. Marjanovic, S.D.; Bogunovic, D.; Milovanovic, M.; Marinkovic, D.; Zdravkovic, N.; Magas, V.; Trailovic, M.S. Antihelminic Activity of Carvacrol, Thymol, Cinnamaldehyde and P-Cymen against the Free-Living Nematode Caenorhabditis Elegans and Rat Pinworm Syphacia Muris. Acta Vet. Beogr. 2018, 68, 445-456. [CrossRef]

25. Hernando, G.; Turani, O.; Bouzat, C. Caenorhabditis elegans muscle Cys-loop receptors as novel targets of terpenoids with potential anthelmintic activity. PLoS Negl. Trop. Dis. 2019, 13, e0007895. [CrossRef]

26. Trailovic, S.M.; Marjanovic, D.S.; Nedeljkovic Trailovic, J.; Robertson, A.P.; Martin, R.J. Interaction of carvacrol with the Ascaris suum nicotinic acetylcholine receptors and gamma-aminobutyric acid receptors, potential mechanism of antinematodal action. Parasitol. Res. 2015, 114, 3059-3068. [CrossRef] 
27. Choudhary, S.; Marjianovic, D.S.; Wong, C.R.; Zhang, X.; Abongwa, M.; Coats, J.R.; Trailovic, S.M.; Martin, R.J.; Robertson, A.P. Menthol acts as a positive allosteric modulator on nematode levamisole sensitive nicotinic acetylcholine receptors. Int. J. Parasitol. Drugs Drug Resist. 2019, 9, 44-53. [CrossRef]

28. Marjanovic, D.S.; Zdravkovic, N.; Milovanovic, M.; Trailovic, J.N.; Robertson, A.P.; Todorovic, Z.; Trailovic, S.M. Carvacrol acts as a potent selective antagonist of different types of nicotinic acetylcholine receptors and enhances the effect of monepantel in the parasitic nematode Ascaris suum. Vet. Parasitol. 2020, 278, 109031. [CrossRef]

29. Courtot, E.; Charvet, C.L.; Beech, R.N.; Harmache, A.; Wolstenholme, A.J.; Holden-Dye, L.; O'Connor, V.; Peineau, N.; Woods, D.J.; Neveu, C. Functional Characterization of a Novel Class of Morantel-Sensitive Acetylcholine Receptors in Nematodes. PLoS Pathog. 2015, 11, e1005267. [CrossRef]

30. Blanchard, A.; Guegnard, F.; Charvet, C.L.; Crisford, A.; Courtot, E.; Sauve, C.; Harmache, A.; Duguet, T.; O'Connor, V.; Castagnone-Sereno, P.; et al. Deciphering the molecular determinants of cholinergic anthelmintic sensitivity in nematodes: When novel functional validation approaches highlight major differences between the model Caenorhabditis elegans and parasitic species. PLoS Pathog. 2018, 14, e1006996. [CrossRef]

31. Beech, R.N.; Neveu, C. The evolution of pentameric ligand-gated ion-channels and the changing family of anthelmintic drug targets. Parasitology 2015, 142, 303-317. [CrossRef]

32. Richmond, J.E.; Jorgensen, E.M. One GABA and two acetylcholine receptors function at the C. elegans neuromuscular junction. Nat. Neurosci. 1999, 2, 791-797. [CrossRef]

33. Raymond, V.; Mongan, N.P.; Sattelle, D.B. Anthelmintic actions on homomer-forming nicotinic acetylcholine receptor subunits: Chicken alpha7 and ACR-16 from the nematode Caenorhabditis elegans. Neuroscience 2000, 101, 785-791. [CrossRef]

34. Boulin, T.; Fauvin, A.; Charvet, C.L.; Cortet, J.; Cabaret, J.; Bessereau, J.L.; Neveu, C. Functional reconstitution of Haemonchus contortus acetylcholine receptors in Xenopus oocytes provides mechanistic insights into levamisole resistance. Br. J. Pharmacol. 2011, 164, 1421-1432. [CrossRef]

35. Abongwa, M.; Buxton, S.K.; Courtot, E.; Charvet, C.L.; Neveu, C.; McCoy, C.J.; Verma, S.; Robertson, A.P.; Martin, R.J. Pharmacological profile of Ascaris suum ACR-16, a new homomeric nicotinic acetylcholine receptor widely distributed in Ascaris tissues. Br. J. Pharmacol. 2016, 173, 2463-2477. [CrossRef]

36. Charvet, C.L.; Guegnard, F.; Courtot, E.; Cortet, J.; Neveu, C. Nicotine-sensitive acetylcholine receptors are relevant pharmacological targets for the control of multidrug resistant parasitic nematodes. Int. J. Parasitol. Drugs Drug Resist. 2018, 8, 540-549. [CrossRef]

37. Trailovic, S.M.; Zurovac, Z.; Gruborovic, S.; Marjanovic, D.S.; Nedeljkovic-Trailovic, J. Presynaptic and postsynaptic regulation of muscle contractions in the ascarid nematode Ascaris suum: A target for drug action. J. Helminthol. 2016, 90, 698-705. [CrossRef]

38. Zheng, F.; Robertson, A.P.; Abongwa, M.; Yu, E.W.; Martin, R.J. The Ascaris suum nicotinic receptor, ACR-16, as a drug target: Four novel negative allosteric modulators from virtual screening. Int. J. Parasitol. Drugs Drug Resist. 2016, 6, 60-73. [CrossRef]

39. Robertson, A.P.; Clark, C.L.; Burns, T.A.; Thompson, D.P.; Geary, T.G.; Trailovic, S.M.; Martin, R.J. Paraherquamide and 2deoxy-paraherquamide distinguish cholinergic receptor subtypes in Ascaris muscle. J. Pharmacol. Exp. Ther. 2002, 302, 853-860. [CrossRef]

40. Sangster, N.C.; Davis, C.W.; Collins, G.H. Effects of cholinergic drugs on longitudinal contraction in levamisole-susceptible and -resistant Haemonchus contortus. Int. J. Parasitol. 1991, 21, 689-695. [CrossRef]

41. Kopp, S.R.; Coleman, G.T.; McCarthy, J.S.; Kotze, A.C. Phenotypic characterization of two Ancylostoma caninum isolates with different susceptibilities to the anthelmintic pyrantel. Antimicrob. Agents Chemother. 2008, 52, 3980-3986. [CrossRef]

42. Martin, R.J.; Robertson, A.P.; Buxton, S.K.; Beech, R.N.; Charvet, C.L.; Neveu, C. Levamisole receptors: A second awakening. Trends Parasitol. 2012, 28, 289-296. [CrossRef]

43. Robertson, A.P.; Bjorn, H.E.; Martin, R.J. Resistance to levamisole resolved at the single-channel level. FASEB J. 1999, 13, 749-760. [CrossRef]

44. Qian, H.; Martin, R.J.; Robertson, A.P. Pharmacology of N-, L-, and B-subtypes of nematode nAChR resolved at the single-channel level in Ascaris suum. FASEB J. 2006, 20, 2606-2608. [CrossRef]

45. Qian, H.; Robertson, A.P.; Powell-Coffman, J.A.; Martin, R.J. Levamisole resistance resolved at the single-channel level in Caenorhabditis elegans. FASEB J. 2008, 22, 3247-3254. [CrossRef]

46. Garcia-Bustos, J.F.; Sleebs, B.E.; Gasser, R.B. An appraisal of natural products active against parasitic nematodes of animals. Parasit. Vectors 2019, 12, 306. [CrossRef]

47. Miro, M.V.; CR, E.S.; Viviani, P.; Luque, S.; Lloberas, M.; Costa-Junior, L.M.; Lanusse, C.; Virkel, G.; Lifschitz, A. Combination of bioactive phytochemicals and synthetic anthelmintics: In vivo and in vitro assessment of the albendazole-thymol association. Vet. Parasitol. 2020, 281, 109121. [CrossRef]

48. Minsakorn, S.; Watthanadirek, A.; Poolsawat, N.; Puttarak, P.; Chawengkirttikul, R.; Anuracpreeda, P. The anthelmintic potentials of medicinal plant extracts and an isolated compound (rutin, C27H30O16) from Terminalia catappa L. against Gastrothylax crumenifer. Vet. Parasitol. 2021, 291, 109385. [CrossRef]

49. Silva, C.R.; Lifschitz, A.L.; Macedo, S.R.D.; Campos, N.; Viana-Filho, M.; Alcantara, A.C.S.; Araujo, J.G.; Alencar, L.M.R.; Costa-Junior, L.M. Combination of synthetic anthelmintics and monoterpenes: Assessment of efficacy, and ultrastructural and biophysical properties of Haemonchus contortus using atomic force microscopy. Vet. Parasitol. 2021, 290, 109345. [CrossRef] 